\title{
Da mania ao suicídio ${ }^{1}$
}

\section{Janderson Farias Silvestre dos Santos 2}

Nas horas que se desagregam, que desfio entre os meus dedos parados, sou a que sabe sempre que horas são, que dia é, o que faz hoje, amanhã, depois. Não sinto deslizar o tempo através de mim, sou eu que deslizo através dele e sinto-me passar com a consciência nítida dos minutos que se passam e dos que se vão seguir. Como compreender a amargura desta amargura? (Espanca, 1982, p.33)

A melancolia é conhecida por uma potencialidade mortífera que se manifesta frequentemente em atos de autodestruição. O melancólico parece estar num constante flerte com a morte e com a possibilidade de saltar no abismo da inexistência. Esse salto em direção ao desconhecido do além-túmulo não pode ser compreendido se não atentarmos para a relação que o sujeito estabelece, antes de tudo, com a vida. Como já dizia Emil Cioran (1949/1995) é a vida que monopoliza o não-sentido e acumula mistérios, inspirando, assim, mais pavor do que a morte. Esta parece ser uma perspectiva pessimista. Ou, poderíamos dizer, uma perspectiva melancólica?

Considerando a vida em suas dimensões antagônicas e conflitantes, a começar pelos conflitos que se dão no interior do próprio sujeito, o melancólico parece, no ato suicida, responder negativamente à pergunta que Albert Camus (1989) diz ser a questão fundamental da filosofia: a vida vale a pena ser vivida? Não. Responderia o melancólico.

É claro que pensar o suicídio em termos de resposta a uma pergunta é reduzir sobremaneira a sua profundidade, pois leva a crer que o problema é puramente da ordem da reflexão intelectual. Evidente que não é esse o caso. O próprio Camus reconhece que ninguém (ou quase ninguém, ele deixa aberta a hipótese) se mata em função de reflexões puramente racionais. O "verme",

\footnotetext{
${ }^{1}$ Este trabalho foi apresentado em "Trabalhos livres" no I Simpósio Bienal "O mesmo, o outro: Psicanálise em movimento" da Sociedade Brasileira de Psicanálise de São Paulo.

${ }^{2}$ Psicólogo, Mestre em Psicologia Clínica pelo IPUSP
} 
ele diz, "se acha no coração do homem. É ali que é preciso procurá-lo. É preciso seguir e compreender esse jogo mortal que arrasta a lucidez em face da existência à evasão para fora da luz" (Camus, 1989, p.24).

Parece ser a busca desta compreensão que subjaz à pergunta da poetisa portuguesa Florbela Espanca citada no início deste trabalho: "Como compreender a amargura desta amargura?" Menos de um ano após questionar-se sobre isso em seu diário, Florbela se suicida, tragada pelo jogo mortal, como diria Camus (1989). Neste trabalho, tento seguir essa pergunta de Florbela, privilegiando o lugar da mania nesse jogo mortal que leva ao suicídio do melancólico.

\section{O trabalho de melancolia}

A poesia de Florbela Espanca, marcada por problemáticas duras da existência, remonta frequentemente ao problema de uma perda primordial e seu principal corolário: a saudade ${ }^{3}$. Assim, por exemplo, O livro d'ele, que, como o próprio título sugere, dedica-se a um objeto de amor, não é iniciado com uma expressão de amor satisfatória. Ao contrário, o poema Junquilhos, que abre o livro, versa sobre a perda/abandono do amante:

Nessa tarde mimosa de saudade

Em que te vi partir, ó meu amor,

Levaste-me a minh'alma apaixonada

Nas folhas perfumadas duma flor. (Espanca, 2002a, p.91)

Dessa perda que recai sobre a obra florbeliana parece derivar um trabalho de luto, trabalho que parece subjazer à toda produção literária florbeliana, como ela mesma aponta no prefácio de seu livro As máscaras do destino, dedicado à memória de seu irmão morto: “(...) eu não queria, não queria que meu morto morresse comigo, não queria! E escrevi estas páginas... Este livro é o livro de um Morto, este livro é o livro do meu Morto.” (Espanca, 1985, p.24).

Os paradigmas da perda e do luto são centrais para a compreensão da dinâmica que constitui a melancolia. Em Luto e melancolia Freud (1917/1996) pontua que assim como existe um trabalho de luto ao final do qual o sujeito enlutado pode fazer novos investimentos objetais,

\footnotetext{
${ }^{3}$ Isto se torna evidente se nos atentarmos para o número de referências diretas e indiretas ao tema da saudade na obra florbeliana. Por exemplo, nas antologias Trocando olhares e O livro d'ele, escritas inicialmente para serem um único livro, há quarenta referências diretas à saudade, dispersas em 33 poemas. Somam-se a isso as referências indiretas, isto é, poemas que versam sobre perda, abandono ou mesmo a impossibilidade de alcançar o objeto de amor e chega-se à marca de 40 poemas Além destes diversos poemas em que é premente o tema da saudade Florbela escreveu um livro inteiro que leva a saudade no título: O livro de Sóror Saudade.
} 
seria plausível supor a existência de um trabalho semelhante na melancolia, isto é, um trabalho de melancolia.

A perda objetal suscitaria, na melancolia, um surto melancólico (Freud, 1933/1996), momento em que a severidade superegóica é amplamente intensificada; no surto o "superego (...) insulta, humilha e maltrata o pobre ego, ameaça-o com os mais duros castigos" (op.cit.p.66), se tornando uma espécie de "lugar de reunião dos instintos de morte" (Freud, 1923/1996, p.68). A saída desse surto, pela via do 'trabalho de melancolia, é o que impede que o sujeito se encaminhe à autodestruição.

No luto normal o processo de desapego está assegurado pelo narcisismo, de maneira que o sujeito é convencido "pela soma das satisfações narcísicas que deriva de estar vivo, a romper sua ligação com o objeto abolido" (Freud, 1917/1996, p.261). Na melancolia, todavia, é precisamente o narcisismo que impede o desapego, pois o vínculo objetal que precede a perda é um vínculo narcísico, o que significa dizer que às relações objetais melancólicas subjaz uma ampla identificação (Freud, 1921/1996), de modo que a identificação com o objeto perdido modifica o ego substancialmente (Freud, 1917/1996).

O melancólico não pode deixar que o objeto se vá sem temer perder-se com ele. Neste contexto, perder o objeto é, nas palavras de Florbela Espanca (2002a, p.128) uma tragédia infinita: “(...) a tragédia infinita é a Saudade!/ (...) a tragédia infinita é Nunca Mais!!” Em outro poema, intitulado $O$ último sonho de Sóror Saudade, a poetisa diz assim:

Sóror Saudade olhou... Que olhar profundo

Que sonha e espera?... Ah! como é feio o mundo.

E os homens vãos! - Então, devagarinho,

Sóror Saudade entrou no seu convento...

E, até morrer, rezou, sem um lamento,

Por Um que se perdera no caminho!... (Espanca, 2002b, p.143)

O que parece estar implícito nesse poema é que a feiura do mundo se dá em função de uma importante perda sofrida por Sóror Saudade, pois o narrador do poema, ao interpelá-la, aponta para essa dimensão da espera: “Que sonha e espera?”, ele pergunta, ao que, em seguida, pela constatação da ausência deste a quem se espera e que se perdeu pelo caminho, cai sobre os ombros do narrador e da própria Sóror a feiura do mundo e a nulidade dos homens. No poema, após a perda desse a quem se espera tudo perde o significado e, na impossibilidade de 
reencontrá-lo, resta apenas à Sóror Saudade retornar ao seu convento, ao seu enclausuramento e aguardar a chegada da morte. Não poderíamos dizer que há aqui, nesse poema, uma descrição poética do que seria um lento suicídio, um matar-se lentamente? Neste contexto, remete à afirmação de Freud (1923/1996) de que a angústia de morte, na melancolia, deriva do ódio devotado ao ego pelo superego, pois para o ego viver significa ser amado pelo superego. Penso que se compreende mais facilmente essa relação se nos atentarmos para a dimensão de Ideal que o superego comporta. Ser amado é estar totalmente ligado ao Ideal. Para o melancólico perder o objeto ideal implica ser lançado à morte.

Benno Rosenberg (2003) argumenta que para que o trabalho de melancolia tenha sucesso, quatro processos psíquicos devem ser assegurados: “(...) a 'destacabilidade’ do objeto (...), a liquidação do investimento narcisista-idealizante do objeto perdido (...), a expressão da raivasadismo para ligá-la e elaborá-la (...) e (...) o encontro com o objeto por meio da transformação do autosadismo em masoquismo" (p.148). No cerne destes componentes estão o narcisismo (os dois primeiros) e a ambivalência (os últimos). Rosenberg (2003) define então o trabalho de melancolia como o "trabalho psíquico elaborativo da "não-destacabilidade”” (p.131, itálicos do autor), trabalho que implica a expressão da raiva-sadismo sobre o objeto introjetado, de modo a realizar a desidealização do objeto, isto é, liquidar o investimento narcisista-idealizante.

Se, por um lado, o sucesso do trabalho de melancolia depende da expressão da raiva, por outro é preciso que ela seja fusionada com componentes eróticos. É necessário, pois, que haja um intenso investimento no ego, de maneira que a raiva-sadismo se torne masoquismo erógeno. Rosenberg (2003) argumenta, a esse respeito, que a formação de um núcleo masoquista erógeno primário é condição de sobrevivência do ego, visto que ele permite que o ego suporte certa quantidade de excitação própria das pulsões de vida sem sucumbir à fragmentação absoluta a que tende a pulsão de morte. Esse processo só é possível pela fusão pulsional que se dá pela libidinização da pulsão de morte. Dessa forma o sujeito sairá da dinâmica autosádica, isto é, uma dinâmica intrapsíquica de agressão recíproca entre as instâncias psíquicas, e caminhará rumo às relações objetais.

\section{A (tentativa de) reparação maníaca}


Na melancolia o sujeito permanece profundamente enredado na utilização de defesas maníacas, sendo o luto melancólico eminentemente maníaco. Dessa forma, penso que tanto o trabalho de melancolia quanto as reparações maníacas são faces do mesmo processo que leva à saída do surto melancólico e impede que o sujeito sucumba ao suicídio.

Jean Michel Petot (2002) diz que a configuração psíquica que Klein descreve como posição depressiva é, na verdade, uma posição maníaco-depressiva. $\mathrm{O}$ autor argumenta que não há na posição depressiva defesas propriamente depressivas e que as reparações que se dão nesta posição são maníacas e obsessivas, como a própria Klein (1940/1996) descreve. Quando o bebê se torna capaz de prescindir dos modos de reparação maníaca e obsessiva significa que a posição depressiva infantil foi superada. Deste modo, diz Petot, “ a reparação autenticamente depressiva é de fato um mecanismo pós-depressivo" (2002, p.24).

Klein (1963/1991) já descrevera que o melancólico deu alguns passos em direção à integração de si e do objeto. Contudo, a principal problemática da dinâmica melancólica é a impossibilidade de reparar o objeto amado e estabelecer de fato uma relação de amor com ele. Sabemos, desde Klein (1940/1996), que toda experiência de luto é uma atualização das ansiedades e defesas da posição depressiva infantil e que o grau de sucesso da elaboração do luto dependerá da forma como foi elaborada a posição depressiva. Desta forma, não tendo podido elaborar satisfatoriamente a posição depressiva, o melancólico permanece enredado em defesas primitivas, predominantemente maníacas, próprias daquela posição.

Um dos componentes presentes na modalidade maníaca de reparação é o triunfo, nas palavras de Petot "o triunfo representa de fato a face, voltada para o objeto, da ilusão de onipotência que infiltra a atitude de reparação da posição maníaca" (p.20). Embora o elemento do triunfo seja parte natural dos períodos iniciais do luto, se ele não é sobrepujado pela reparação real esta fica comprometida, de maneira que a culpa não é aliviada, levando o ego a empreender um reforço das defesas maníacas, o que leva à instauração de um círculo maligno em que a intensificação da culpa incrementa a violência das defesas. O sujeito então necessita sobrepor-se cada vez mais ao objeto, triunfar sobre ele, sendo a idealização uma outra face do triunfo. Ora, em cada experiência de luto melancólico há um reforço deste círculo maligno que, gradualmente, se encaminha ao paroxismo. 
Ao invés de o triunfo ser, como no luto normal, uma fase no andamento do trabalho de luto, sendo superado por reais trabalhos de reparação, no melancólico o desfecho do triunfo parece se dar ou pela destruição onipotente do objeto, após a destacabilidade efetuada pelo trabalho de melancolia, ou por uma intensificação da idealização, o que pode culminar no ato suicida.

Nesse contexto, o suicídio aparece como possibilidade, aparentemente paradoxal, de fugir da angústia de morte que Freud (1923/1996) já observara existir no melancólico. O paradoxo se resolve se compreendemos que essa fuga não se dá para o vazio, isto é, para a aniquilação absoluta. O suicídio do melancólico somente é possível por conta da outra face da aniquilação, a saber, a idealização, um importante elemento que subjaz às defesas maníacas. A saída para a mania, sendo efetuada pelo elemento do triunfo, implica, de um lado, a negação da realidade psíquica, principalmente a experiência da ambivalência e da culpa que ela implica, e, de outro, a manutenção de uma parte idealizada do ego. A esse respeito, vejamos os dois quartetos do soneto florbeliano Versos de orgulho:

O mundo quer-me mal porque ninguém

Tem asas como eu tenho! Porque Deus

Me fez nascer Princesa entre plebeus

Numa torre de orgulho e de desdém!

Porque o meu Reino fica para Além!

Porque trago no olhar os vastos céus,

E os oiros e os clarões são todos meus!

Porque Eu sou Eu e porque Eu sou Alguém! (Espanca, 2002b, p.58)

Não é difícil perceber aqui a expressão de uma exaltação maníaca. Acredito que o investimento no ego e a expressão do sadismo que propiciam a destacabilidade do objeto no trabalho de melancolia são também a expressão da exaltação maníaca, na medida em que o investimento permite que o ego se sobreponha narcisicamente ao objeto, que perde então a função de ideal, permitindo que o ego se volte a outros relacionamentos objetais. Freud (1917/ 1996) já havia observado que o apetite maníaco voraz por novos relacionamentos objetais demonstra a saída do enclausuramento ego/objeto que se dá no surto melancólico.

Enquanto no desenvolvimento saudável o círculo benigno das gratificações propicia a aproximação do ego e do ideal, na constituição melancólica o círculo maligno das defesas maníacas aumenta cada vez mais a fosso entre o ego e o ideal, o que, por sua vez, é acompanhado por uma desfusão pulsional cada vez mais profunda, amplificando, a cada 
experiência de perda, a dificuldade de religação das pulsões pelo trabalho de melancolia e, consequentemente, a saída do surto melancólico para a mania.

O elemento do triunfo implica a fantasia de conter dentro de si o objeto idealizado. Klein (1940/1996, p.398) diz que a exaltação maníaca está associada "à sensação de trazer o objeto amado perfeito (idealizado) dentro de si”. A relação com esse objeto, ainda que perpassada por um superinvestimento libidinal, é fruto de uma relativa fusão pulsional, pois ela permite que o melancólico se volte às relações objetais. A gradual intensificação da violência das defesas maníacas que se perfaz no círculo maligno, ao mesmo tempo em que deriva da desfusão pulsional, potencializa essa desfusão. Ao chegar ao ápice essas defesas levam exatamente ao contrário de seu objetivo, isto é, transforma o relacionamento objetal com o objeto ideal em um colamento absoluto.

O suicídio do melancólico parece se dar, portanto, numa conjunção de fatores, a saber, de um lado a ação da pulsão de morte desfusionada sobre uma parte do ego e, de outro, a ação da pulsão libidinal também desfusionada sobre a outra parte, intensificando a fantasia de fusão absoluta que subjaz à idealização. O que há nesse caso, em última análise, é o paroxismo do processo que Freud (1917/ 1996) já havia observado acontecer no surto melancólico, isto é, uma cisão entre o amor, que encontra refúgio na identificação narcísica e o ódio, que é tomado pelo superego.

Se a conversão em mania é o que impede a autodestruição do melancólico, o suicídio do melancólico se daria então no fracasso das defesas maníacas? Ao meu ver ele é, paradoxalmente, concomitantemente fruto do fracasso e do sucesso. O paradoxo se dá no fato de que a mania só pode se configurar numa saída do surto melancólico em direção à preservação da vida se houver um fracasso relativo dessa conversão. O que quero dizer é que o objetivo último da mania é a confluência absoluta do ego e do ideal. Essa confluência só pode se dar numa desfusão absoluta das pulsões, o que, em última instância, é a morte.

A identificação narcísica, mesmo sendo mais ampla que a identificação por traços, ainda não é absoluta. É a parcialidade da identificação que permite alguma abertura para a alteridade, impedindo que o sujeito se enclausure completamente num sistema libidinalmente fechado. Deste modo, ao me referir ao fracasso relativo da conversão da melancolia à mania estou pontuando que esse fracasso ou, olhando inversamente, o sucesso relativo, é o que permite a 
saída do enclausuramento narcísico e o movimento rumo às relações objetais, mesmo que ainda narcísicas. Esse fracasso relativo só é alcançado porque mesmo o intenso investimento libidinal é ainda acompanhando de certo nível de fusão das pulsões, o que é efetuado pelo trabalho de melancolia. Somente na desfusão absoluta é que a conversão para a mania seria absoluta. Se, de um lado, isso representa o sucesso do objetivo último da conversão para a mania, de outro, representa o fracasso da mania enquanto possibilidade de saída do surto melancólico e para longe do horizonte do suicídio.

\section{Considerações Finais}

Finalizo minha fala tecendo um comentário a respeito do desamparo humano. Zeferino Rocha (1999) observa que a abertura para as relações alteritárias é a face positiva do desamparo, mas essa abertura só pode constituir-se no encontro com o outro que, ouvindo o grito de socorro do desamparado, o auxilia na busca de sentido e no enfrentamento da condição de desamparo. A saída do surto melancólico é, por assim dizer, uma renovação do grito, um clamor pelo outro, o que implica, em algum nível, uma dose de esperança. Quando o sujeito se lança ao suicídio significa que essa esperança, se não alcançou completamente a extinção, está muito próxima dela.

\section{Referências}

Camus, A. (1989). O mito de Sísifo: ensaio sobre o absurdo. Rio de Janeiro: Guanabara.

Cioran, M. (1949). Breviário de decomposição. Rio de Janeiro: Rocco. (trabalho original publicado em 1949)

Espanca, F. (2002a). Poesia de Florbela Espanca, v.I. Porto Alegre: L\&PM

Espanca, F. (2002b). Poesia de Florbela Espanca, v.II. Porto Alegre: L\&PM.

Espanca, F. (1985). Contos e diário. In Obras completas de Florbela Espanca, vol. IV. Lisboa: publicações Dom Quixote.

Freud, S. (1996). Luto e melancolia. In A história do movimento psicanalítico, Artigos sobre a metapsicologia e outros trabalhos. Rio de Janeiro: Imago. (trabalho original publicado em 1917) 
Freud, S. (1996). Psicologia de grupo e análise do ego. In Além do princípio do prazer, Psicologia de grupo e outros trabalhos. Rio de Janeiro: Imago. (trabalho original publicado em 1921)

Freud, S. (1996). O ego e o id. In $O$ ego e o id e outros trabalhos. Rio de Janeiro: Imago. (trabalho original publicado em 1923)

Freud, S. (1996). Conferência XXXI: a dissecção da personalidade psíquica. In Novas conferências introdutórias sobre psicanálise e outros trabalhos). Rio de Janeiro: Imago. (trabalho original publicado em 1933).

Klein, M. (1996). O luto e sua relação com os estados maníaco-depressivos. In Amor, culpa e reparação e outros trabalhos. Rio de Janeiro: Imago. (trabalho original publicado em 1940)

Klein, M. (1996). Sobre o sentimento de solidão. In Inveja e gratidão e outros trabalhos. Rio de Janeiro: Imago. (trabalho original publicado em 1963).

Petot, J.M (2002). Melanie Klein II: o ego e o bom objeto. São paulo: Perspectiva.

Rocha, Z. (1999). Desamparo e metapsicologia: para situar o conceito de desamparo no contexto da metapsicologia freudiana. Síntese - Rev. de Filosofia. 26 (86). 331-346

Rosenberg, B. (2003) Masoquismo mortífero e masoquismo guardião de vida. São Paulo: Escuta. 